\title{
Estudos sobre a Tríade Formação de Professores, Estágio Supervisionado e Relação Teoria-prática no Ensino de Química: Construindo o Estado da Questão
}

\author{
Manuel Bandeira dos Santos Neto \\ Raphael Alves Feitosa
}

\begin{abstract}
RESUMO
Este estudo apresenta um mapeamento das pesquisas brasileiras ao nível de Pós-Graduação stricto sensu defendidas entre 2013 a 2017. Logo, objetiva analisar as contribuições de dissertações e teses sobre a tríade formação de professores, estágio supervisionado e relação teoria e prática no ensino de Química. Trata-se de um estudo do tipo Estado da Questão (EQ) que busca evidenciar as contribuições de um determinado objeto de estudo para uma área específica do conhecimento. Assumindo esses aspectos, o EQ caracteriza-se como uma pesquisa exploratória. Nesse viés, o levantamento foi efetuado no Banco de Dissertações e Teses da Coordenação de Aperfeiçoamento de Pessoas de Nível Superior (CAPES) e no site da Biblioteca Digital Brasileira de Teses e Dissertações (BDTD), porque são os principais repositórios das pesquisas brasileiras em nível de Pós-Graduação. Foram encontrados 11 trabalhos, entre dissertações e teses, relacionados aos descritores. Isso mostra que existem poucas pesquisas relacionadas aos descritores e embasa a relevância deste levantamento para a comunidade acadêmica. Além disso, demonstra a importância de realizar novas pesquisas para fortalecer a discussão sobre a formação de professores para o ensino de Química no âmbito da Pós-Graduação.

Palavras-chave: Formação Professores. Estágio Supervisionado. Ensino de Química. Estado da Questão.

Manuel Bandeira dos Santos Neto é Licenciado em Química. Atualmente, é Mestrando pelo Programa de PósGraduação em Ensino de Ciências e Matemática (PGECM) do Instituto Federal de Educação, Ciência e Tecnologia do Ceará (IFCE), Bolsista da CAPES e Professor do Governo do Estado do Ceará. Endereço para correspondência: IFCE, sala do PGECM, Av. 13 de Maio, 2081, Benfica, 60040-531, Fortaleza/CE.

E-mail: manoelbandeirasn13@gmail.com

Raphael Alves Feitosa é Doutor em Educação, Mestre em Educação Brasileira. Atualmente é Professor do Departamento de Biologia da Universidade Federal do Ceará (UFC) e do Programa de Pós-Graduação em Ensino de Ciências e Matemática (PGECM) do IFCE. Endereço para correspondência: IFCE, sala do PGECM, Av. 13 de Maio, 2081, Benfica, Cep:60040-531, Fortaleza/CE. E-mail: raphael.biologia@gmail.com

Recebido para publicação em 4 jul. 2018. Aceito, após revisão, em 10 set. 2018.

DOI: https://doi.org/10.17648/acta.scientiae.v20iss5id4551.
\end{abstract}

Acta Scientiae

Canoas

v. 20

n.5

p.831-846

set./out. 2018 


\title{
Studies on the Triad Teacher Training, Supervised Internship and Theory-practice Relationship in Chemistry Teaching: Building the State of the Question
}

\begin{abstract}
This study presents a mapping of the Brazilian researches at the level of Post-Graduation sensu stricto defended between 2013 to 2017. Thus, it aims to analyze the contributions of dissertations and theses on the triad teacher training, supervised internship and relation theory and practice in the teaching of Chemistry. This is a State of the Question study that seeks to highlight the contributions of a given object of study to a specific area of knowledge. Assuming these aspects, the State of the Question is characterized as an exploratory research. In this bias, the survey was carried out in the Banco de Dissertações e Teses da Coordenação de Aperfeiçoamento de Pessoas de Nível Superior (CAPES) and in the website of the Biblioteca Digital Brasileira de Teses e Dissertações (BDTD) because they are the main repositories of Brazilian research at the level post graduate. We found 11 papers, among dissertations and theses related to the descriptors. This shows that there is little research related to the descriptors and bases the relevance of this survey to the academic community. In addition, it demonstrates the importance of conducting new research to strengthen the discussion on teacher education for the teaching of Chemistry in the scope of Post-Graduation. Question.

Keywords: Teacher Training. Supervised internship. Chemistry teaching. State of the

\section{FORMAÇÃO DE PROFESSORES DE QUÍMICA E O ESTÁGIO SUPERVISIONADO: RELAÇÃO ENTRE TEORIA E PRÁTICA}

Nos últimos anos, a formação de professores tem sido um tema recorrente nas pesquisas sobre educação e ensino, especialmente, para entender os processos que norteiam essa formação (Silva, 2016). Segundo Corrêa (2013) desde a década de 30 do século XX, período em que surgiram os cursos de licenciatura, os professores são formados a partir de uma corrente de pensamento positivista caracterizada pela formação de profissionais técnicos especializados em transmitir conhecimento, conhecida como racionalidade técnica.

Esse modelo de formação baseado na racionalidade técnica tem como características a formação do professor como um "técnico-especialista" (Corrêa, 2013; Corrêa, 2015), um profissional que desenvolverá seu trabalho pela aplicação de teorias e técnicas científicas.

O modelo da racionalidade técnica reconhece a prática profissional como um lugar de atuação do professor que, através de ações racionais aplica seu repertório de técnicas para a solução de problemas. A prática diária do professor consiste em aplicar de forma coerente o conhecimento que possui (Corrêa, 2015, p.38) 
Fica evidente que a formação docente baseada nesse modelo põe em destaque o conhecimento teórico. Corrêa (2015, p.38) expõe que o "sucesso do professor estaria relacionado à capacidade de aplicar as técnicas, os procedimentos e metodologias [...]" no processo de aprendizagem. Diante disso, ao analisar os cursos de formação de professores, particularmente para o ensino de Química, notam-se concepções mais teóricas (conteúdos específicos de Química), do que práticas (conteúdos pedagógicos).

Nessa perspectiva, Carvalho e Gil-Pérez (1995) afirmam que a formação de professores de ciências é a junção de uma formação científica aprofundada e uma formação psicossocial e pedagógica superficial. Essa ideia formativa demonstra a tendência dos cursos de formação de professores para atuação em disciplinas como Química, Física, Biologia e tantas outras, de seguirem o modelo da racionalidade técnica: privilegia o conteúdo e deixa em segundo plano as disciplinas de caráter pedagógico e social, como didática, prática de ensino, metodologia da pesquisa, estágio supervisionado, dentre outras (Arrigo, 2015).

Contudo, as Diretrizes Curriculares (DC) para cursos de Licenciatura plena em Química (Brasil, 2001, p.4) estabelecem que:

O Licenciado em Química deve ter formação generalista, mas sólida e abrangente em conteúdo dos diversos campos da Química, preparação adequada à aplicação pedagógica do conhecimento e experiências de Química e de áreas afins na atuação profissional como educador na educação fundamental e média.

Esse é o perfil que deve ter os profissionais formados nos cursos de licenciatura em Química do país (Brasil, 2001). Somam-se a essa perspectiva os princípios que norteiam a base comum nacional para a formação inicial e continuada, dispostos para atender a: "a) sólida formação teórica e interdisciplinar; b) unidade teoria-prática; c) trabalho coletivo e interdisciplinar; d) compromisso social e valorização do profissional da educação; e) gestão democrática; f) avaliação e regulação dos cursos de formação" (Brasil, 2015, p.2).

Porém, com base nas pesquisas desenvolvidas por Corrêa (2013), Ramos (2014), Alves dos Santos (2017) e outros, percebe-se uma formação sólida em conteúdos nas várias áreas da Química, mas insípida em bases pedagógicas. A maioria dos cursos de professores de Química prioriza as disciplinas específicas ao longo do curso, deixando em segundo plano as disciplinas pedagógicas. E, mesmo quando existe um aprofundamento ou uma relação maior entre essas disciplinas, há uma ausência da relação teoria e prática (Maldaner, 2006).

Isso fica mais evidente na formação dos licenciandos quando se observa as matrizes curriculares, já que existe um destaque para a formação do químico, enquanto a formação do professor ou educador em Química é deixada em segundo plano (Ramos, 2014). Sobretudo, porque os futuros docentes são concebidos com o pensamento de que o saber Químico é suficiente para lecionar (Maldaner, 2006). 
Diante disso, esta investigação objetiva analisar as dissertações e teses desenvolvidas no Brasil sobre a tríade formação de professores, estágio supervisionado e relação teoria e prática no ensino de Química para que diante desses dados possa se traçar o cenário investigativo e revelar o que dizem as pesquisas brasileiras em nível de Pós-Graduação stricto sensu sobre esses temas. A temática se insere com a dissertação que está sendo desenvolvida dentro do Programa de Pós-Graduação em Ensino de Ciências e Matemática (PGECM) do Instituto Federal de Educação, Ciência e Tecnologia do Ceará (IFCE), a qual essa pesquisa é um recorte.

Além disso, a presente investigação buscou fundamentar a relevância do objeto de estudo da dissertação da qual ela é parte integrante, construindo o Estado da Questão(EQ) para que o pesquisador e os leitores visualizem o cenário em que o objeto está situado e compreendam as contribuições desse novo trabalho, diante de outras pesquisas de PósGraduação stricto sensu já realizadas.

\section{ESTADO DA QUESTÃO: ASPECTOS TEÓRICOS E OS CAMINHOS PARA SUA CONSTRUÇÃO}

O Estado da Questão (EQ) consiste em uma abordagem teórica por assumir as características de revisão da literatura e metodológica por utilizar diferentes métodos para construir o cenário da questão investigada. Diante disso, o EQ busca evidenciar as contribuições de um determinado objeto de estudo para uma área específica de conhecimento (Nóbrega-Therrien \& Therrien, 2004). Logo, ele é um levantamento criterioso, feito a partir de uma análise crítica das produções encontradas para que o pesquisador possa destacar a relevância de seu objeto de estudo (Nóbrega-Therrien \& Therrien, 2010).

A elaboração do EQ está intrinsecamente ligada com a necessidade de compreender como se encontram as pesquisas realizadas sobre determinado assunto; os métodos utilizados para realizar determinada pesquisa para que o pesquisador possa situar e delimitar seu objeto de investigação (Nóbrega-Therrien \& Therrien, 2004).

Diante do exposto, o EQ auxilia o pesquisador a construir o cenário de pesquisas e estudos na sua área de interesse, através de um mapeamento da literatura disponível, ao estabelecer um diálogo com os autores consultados para fundamentar conexões, concordâncias e discordâncias a respeito do objeto de estudo (Nóbrega-Therrien \& Therrien, 2010). Portanto, o EQ fomenta as contribuições da pesquisa para o conhecimento científico no campo estudado.

Assumindo esses aspectos, o EQ caracteriza-se como uma pesquisa exploratória, pois proporciona "maior familiaridade com o problema, com vista a torná-lo mais explícito ou a construir hipóteses" (Gil, 2017, p.26). Além disso, sua organização é flexível, porque considera "os mais variados aspectos relativos ao fato ou fenômeno estudado" (Gil, 2017, p.26). 
Logo, o EQ direciona a sua investigação para uma determinada área de conhecimento, onde ele vai explorar e investigar diferentes aspectos dentro desse assunto para, a partir disso, delimitar e caracterizar o seu objeto (Nóbrega-Therrien \& Therrien, 2010).

Nessa perspectiva, o pesquisador poderá usar muitos meios de investigação, mas ele deve escolher aqueles que atendem as necessidades diretas do seu objeto de pesquisa. Por isso, como esse artigo está diretamente relacionado a uma pesquisa de Pós-Graduação stricto sensu, optamos por mapear dissertações e teses.

A partir disso, escolhemos como meios de consulta para esse levantamento o Catálogo de Teses e Dissertações da Coordenação de Aperfeiçoamento de Pessoas de Nível Superior $\left(\mathrm{CAPES}^{1}\right)$ e a Biblioteca Digital Brasileira de Teses e Dissertações $\left(\mathrm{BDTD}^{2}\right)$, porque esses são os principais repositórios das pesquisas brasileiras em nível de Pós-Graduação.

Ao iniciar o levantamento, definiram-se quais os descritores (palavras-chave) que seriam usados: formação de professores de Química; estágio supervisionado em Química; relação teoria e prática em Química. Esses são norteadores nessa investigação. Também se definiu que a busca seria realizada por trabalhos defendidos entre 2013 a 2017, optouse por esse espaço temporal porque no Catálogo da CAPES o acervo antes de 2013 não havia sido digitalizado.

Ao realizar a busca usando os descritores sem o uso de aspas, no Catálogo da CAPES, foi encontrada uma quantidade total de 2.889 .619 pesquisas, entre dissertações e teses, conforme disposto no Quadro 1, a seguir.

Quadro 1

Quantidade de teses e dissertações encontradas no Banco da CAPES buscando pelos descritores sem aspas.

\begin{tabular}{|c|c|}
\hline Descritores & Total encontrado \\
\hline Formação de professores de Química & 986.868 \\
\hline Estágio supervisionado em Química & 917.248 \\
\hline Relação teoria e prática em Química & 985.503 \\
\hline Total & $\mathbf{2 . 8 8 9 . 6 1 9}$ \\
\hline
\end{tabular}

Diante da quantidade de pesquisas encontradas, optou-se por utilizar os descritores entre aspas para evitar resultados desarticulados com a temática da investigação, porque ao realizar uma leitura superficial dos dados encontrados foi possível verificar pesquisas que não estavam alinhadas com os descritores.

\footnotetext{
$\overline{1} \mathrm{http}: / /$ catalogodeteses.capes.gov.br/catalogo-teses.

2 http://bdtd.ibict.br/vufind/.
} 
Além disso, os descritores não são suficientes para escolher se uma pesquisa é relevante ou não para o pesquisador. Logo, foram definidos critérios de exclusão e inclusão. Assim, adotou-se como critérios de inclusão: correspondências com os descritores e a relação com objeto de estudo da dissertação em andamento; como critério de exclusão: leitura do resumo e objetivos das dissertações e teses. O Quadro 2, apresenta a quantidade de trabalhos encontrados e os que são relativos (relacionadas com o objeto investigado) como base nos critérios adotados.

Quadro 2

Quantidade de teses e dissertações encontradas no Catálogo da CAPES buscando pelos descritores com aspas.

\begin{tabular}{|c|c|c|}
\hline Descritores & Total encontrado & Relativos \\
\hline Formação de professores de Química & 82 & 08 \\
\hline Estágio supervisionado em Química & 02 & 02 \\
\hline Relação teoria e prática em Química & 00 & 00 \\
\hline Total & 84 & 10 \\
\hline
\end{tabular}

Após o levantamento no Catálogo da Capes, iniciou-se o levantamento na Biblioteca Digital Brasileira de Teses e Dissertações (BDTD). O quadro 3 mostra a quantidade de dissertações e teses encontradas com a busca pelos descritores e os trabalhos relativos. Destaca-se que entre os trabalhos relativos encontrados, alguns se repetem para diferentes descritores, por isso a quantidade total são 5 trabalhos.

Quadro 3

Quantidade de teses e dissertações encontradas na BDTD.

\begin{tabular}{|c|c|c|}
\hline Descritores & Total encontrado & Relativos \\
\hline Formação de professore de Química & 309 & 04 \\
\hline Estágio supervisionado em Química & 14 & 02 \\
\hline Relação teoria e prática em Química & 44 & 01 \\
\hline Total & 367 & $\mathbf{0 5}$ \\
\hline
\end{tabular}

Depois dos resultados iniciais apresentados no mapeamento e a partir da leitura das dissertações e teses encontradas no banco de Dissertações e Teses da Capes e na Biblioteca Digital Brasileira de Teses e Dissertações, constatou-se que são poucas as pesquisas relacionadas aos descritores pesquisados. Porém, ao analisar os objetivos dos trabalhos notou-se a intrínseca relação deles com o objeto de estudo da pesquisa de mestrado que está sendo desenvolvida, visto que as dissertações e teses investigam os processos 
formativos, as práticas pedagógicas, o estágio supervisionado e as suas contribuições para a formação de professores de Química.

Além disso, observou-se nos trabalhos analisados a necessidade por compreender o cenário educacional e suas implicações na formação de professores, com o viés de estimular a reflexão e o posicionamento crítico dos futuros docentes. Ademais, percebeuse a preocupação com exercício da práxis: os desafios, as preocupações e as inseguranças do primeiro contato dos licenciandos e dos licenciados com a sala de aula.

Nesse aspecto, compreender as contribuições do estágio supervisionado na formação de professores e sua relação com a parte teórica e prática (vivência do ambiente escolar) torna-se cada vez mais relevante; como também, entender como se estrutura, como se desenvolve e como o estágio supervisionado impacta na formação e no trabalho docente.

Por isso, o Quadro 4 apresenta uma síntese dos trabalhos encontrados e seus objetivos para a partir disso; da leitura dos referenciais e das metodologias utilizadas nas pesquisas, apresentar a análise dessas produções na perspectiva da tríade formação de professores, estágio supervisionado e relação teoria e prática no ensino de Química.

Destaca-se que estão descritos um total de 11 trabalhos que com base nos critérios de inclusão foram considerados relativos. Nos Quadros 2 e 3, apresentam 10 e 5 trabalhos respectivamente, contudo alguns trabalhos se repetiam na busca, tanto no Banco da CAPES com na BDTD, por isso o total de 11 trabalhos, entre dissertações e teses detalhados abaixo.

Quadro 4

Síntese das produções encontradas no Catálogo da CAPES e na BDTD.

Autor: Santos, D. M.

Tema: Discutindo a formação dos professores de Química da região noroeste do Paraná e suas práticas pedagógicas.

Objetivo: Investigar a formação e as práticas pedagógicas dos professores, identificando suas necessidades formativas no intuito de contribuir para uma formação mais eficiente e efetiva desses professores.

Ano: 2016 Local/IES/Tipo: Capes/UNESPAR/Dissertação

Autor: Fonseca, C. V.

Tema: A formação de professores de Química em instituições de ensino superior do Rio Grande do Sul: saberes, práticas e currículos.

Objetivo: Caracterizar o cenário internacional da Educação, bem como as questões envolvendo indicadores educacionais, a formação e o trabalho docente no Brasil; situar a área da formação docente em Química nos contextos citados, incluindo o perfil dos cursos e estudantes.

Ano: 2014 Local/IES/Tipo: Capes/UFGRS/Tese 
Autor: Silva, D.

Tema: Análise da prática docente na formação de professores de Química.

Objetivo: Investigar e analisar o processo acadêmico-profissional e os referencias pedagógicos dos professores formadores do curso de Licenciatura em Química do Instituto Federal Farroupilha - Campus Alegrete

Ano:2016 Local/IES/Tipo: Capes/UFRGS/Tese

Autor: Vacheski, G.M.O.

Tema: Atividades sob a perspectiva CTS na formação inicial de professores de Química: implicações para o desenvolvimento profissional docente

Objetivo: Compreender o processo de formação docente de dois estudantes do curso de licenciatura em Química de uma Universidade Estadual Paranaense durante os estágios supervisionados e as suas reflexões no decorrer do planejamento, da execução e da avaliação das atividades, que compõem uma Sequência Didática sob o enfoque ciência, tecnologia e sociedade (CTS)

Ano: 2016 Local/IES/Tipo: Capes e BDTD/UEL/Dissertação

Autor: Ramos, D.V. B

Tema: Formação de professores de Química na Amazônia: um estudo na Universidade Federal de Rondônia

Objetivo: Compreender o processo de formação do professor de Química na Universidade Federal de Rondônia/UNIR para atender ao perfil proposto em seu PPP, com destaque nas experiências vividas por seus protagonistas.

Ano: 2014 Local/IES/Tipo: Capes/UNIR/Dissertação

Autor: Correa, T. H. B.

Tema: Os anos iniciais da docência em Química: da universidade ao chão da escola

Objetivo: Revelar quais são as principais dificuldades vivenciadas pelos entrevistados, como eles vêm tentando superá-las, além de problematizar os possíveis impactos do primeiro contato docente com a realidade das salas de aula.

Ano: 2013 Local/IES/Tipo: Capes/UNIMEP/Dissertação

Autor: Alves Dos Santos, J. D.

Tema: A formação no curso de licenciatura em Química UFG/Goiânia: a relação entre a formação e o trabalho docente

Objetivo: Compreender de que forma a relação entre a formação e o trabalho docente durante a formação dos licenciandos de Química da UFG/Goiânia

Ano: 2017 Local/IES/Tipo: Capes/UFG/Tese

Autor: Castro, S. I.

Tema: Concepções de licenciandos do curso de Química da Universidade Federal de Juiz de Fora e professores de química da educação básica sobre o estágio supervisionado

Objetivo: Conhecer as concepções de professores de Química da educação básica e licenciandos do curso de Química da UFJF a respeito da estrutura e desenvolvimento do Estágio, visando compreender como o envolvimento de professores formados e em formação oriundos de cursos de licenciatura de diferentes modelos impactam na formação desses sujeitos.

Ano: 2014 Local/IES/Tipo: Capes e BDTD/UFJF/Dissertação 
Autor: Correa, R. G.

Tema: Formação inicial de professores de Química: discursos, saberes e práticas.

Objetivo: Investigar e analisar a proposta formativa para a formação inicial de professores de Química nos cursos de licenciatura em Química das instituições de ensino superior do estado de São Paulo

Ano: 2015 Local/IES/Tipo: Capes e BDTD/UFSCar/Tese

Autor: Arrigo, V.

Tema: Estudo sobre as reflexões dos licenciandos em Química nas atividades de microensino: implicações para a formação inicial docente

Objetivo: Identificar, nas falas, as situações decorrentes das suas práticas de ensino que os levaram a refletir para resolver eventual problema da prática, situações essas denominadas "alerta"; identificar, por meio da reflexão sobre a reflexão-na-ação, os "momentos" de estruturação, questionamento e reestruturação que levaram os estudantes a planejarem uma nova ação; identificar as implicações que a estratégia da autoscopia bifásica, nos moldes da "sala de espelhos" proposta por Schön, causam na construção do perfil docente desses estudantes.

Ano: 2015 Local/IES/Tipo: Capes e BDTD/UEL/Dissertação

Autor: Suart, R. C.

Tema: Formação inicial de professores de Química: o processo de reflexão orientada visando o desenvolvimento de práticas educativas no ensino médio

Objetivo: Investigar as contribuições do processo de reflexão orientada na atuação pedagógica de licenciandos em Química, visando um ensino por investigação e para a promoção da alfabetização científica no Ensino Médio.

Ano: 2016 Local/IES/Tipo: BDTD/USP/Tese

As dissertações e teses encontradas nos repositórios investigados revelaram que o número de pesquisas em relação à tríade formação de professores, estágio supervisionado e relação teoria e prática no ensino de Química tem aumentado. Observando o Quadro 5, nota-se que o ano de 2016 foi o que apresentou uma maior quantidade de pesquisas relacionadas aos descritores.

Quadro 5

Evolução da abordagem dos descritores em dissertações e teses.

\begin{tabular}{|l|c|c|c|c|c|}
\hline Tipo de publicação & $\mathbf{2 0 1 3}$ & $\mathbf{2 0 1 4}$ & $\mathbf{2 0 1 5}$ & $\mathbf{2 0 1 6}$ & $\mathbf{2 0 1 7}$ \\
\hline Dissertações & 1 & 2 & 1 & 2 & 0 \\
\hline Teses & 0 & 1 & 1 & 2 & 1 \\
\hline Subtotal & 1 & 3 & 2 & 4 & 1 \\
\hline Total & \multicolumn{7}{|c|}{$\mathbf{1 1}$} \\
\hline
\end{tabular}

Os trabalhos encontrados relativos aos descritores com base nos critérios de inclusão foram interpretados com base na técnica análise de conteúdo. No pensamento de Franco 
(2005, p.13) "o ponto de vista da Análise de Conteúdo é a mensagem, seja ela verbal (oral ou escrita), gestual, silenciosa, figurativa, documental ou diretamente provocada" (grifos da autora). Essa mensagem expressa pelo interlocutor está carregada de significados e sentidos que foram construídos pelas interações do sujeito com as pessoas, com o ambiente (Bardin, 2016).

Essa análise buscou evidenciar convergências, divergências, contribuições e pontos de vista das dissertações e teses em relação à dissertação de mestrado em andamento, da qual esse estudo faz parte. A seguir, apresenta-se essa análise.

\section{PONTOS DE VISTA E CONTRIBUIÇÕES DAS DISSERTAÇÕES E TESES}

Santos (2016) investigou, em sua pesquisa, quais seriam as necessidades do professor de Química frente à ação pedagógica. No desenvolver do trabalho, destaca-se o comprometimento com a articulação teoria e prática: elemento transformador da prática pedagógica, "superando modelos reducionistas e fragmentados de conhecimento para ações mais significativas que permitam a troca de saberes” (p.17).

Seguindo esse panorama o autor fez uma abordagem histórica sobre a formação de professores, sobretudo, em Química discutindo a formação inicial frente o modelo de racionalidade técnica que distancia a teoria da prática (Santos, 2016). Na fundamentação teórica sobre esse assunto, ficou clara a formação de bacharéis em Química, mesmo quando o curso era de licenciatura. Havia e ainda há uma preocupação maior com o conteúdo químico, do que com a formação pedagógica.

Posteriormente são enfatizadas as "práticas pedagógicas no processo de ensino e aprendizagem de Química" para compreensão das estratégias utilizadas em sala de aula, da relação professor e aluno, e o desenvolvimento docente para a ação-reflexão-ação dentro da associação teoria e prática.

Fonseca (2014) analisou a formação de professores de Química em diferentes instituições de ensino superior do estado do Rio Grande do Sul (RS) para compreender como os saberes, práticas e o currículo contribuem na formação docente. Ao final da pesquisa, o autor destacou em suas considerações a predominância de uma aprendizagem voltada para conhecimentos "específicos de Química" e a ausência de "fundamentos teóricos sobre educação e outros conhecimentos específicos para a docência” (p.8).

Esse e outros dados coletados do cenário da formação de professores do RS mostram a pouca interação entre disciplinas específicas e pedagógicas nas matrizes curriculares dos cursos de Licenciatura em Química, resultando na falta de comprometimento no desenvolvimento da prática docente.

Já Silva (2016, p.14) buscou identificar quem são os profissionais que estão formando os licenciandos e como eles estão desenvolvendo a atividade de formar professores de Química no RS, a partir do entendimento de como esses formadores compreendem o 
processo de formação docente e quais são "referenciais didáticos - metodológicos" que são usados.

Trilhando esse caminho, a autora faz um levantamento histórico da formação de professores para caracterizar o cenário atual, apontando a necessidade dos cursos de licenciatura em desenvolverem profissionais além da aprendizagem conteudista, que sejam capazes de integrar os diferentes saberes em sua prática.

Nessa mesma perspectiva, Vacheski (2016) procurou compreender o processo de formação de licenciandos em Química de uma universidade do Paraná durante os estágios supervisionados e os mecanismos envolvidos na construção de uma sequência didática nos aspectos de ciência, tecnologia e sociedade (CTS).

A autora destaca a necessidade de uma formação que forneça subsídios aos professores para ultrapassarem as barreiras de um ensino pautado só nos conteúdos. $\mathrm{O}$ processo de ensino não deve fundamentar só a base científica dos educandos, mas a sua aplicação para compreender o mundo e suas relações com a disciplina de Química. Não deve haver rupturas, mas vislumbrar possibilidades de mudanças de "natureza social, política, econômica ou ambiental" (Vacheski, 2016, p.15). A formação deve desenvolver a práxis, não a limitar.

Em um estudo semelhante ao de Vacheski (2016), o pesquisador Ramos (2014) procurou compreender como são formados os professores de Química da Universidade Federal de Rondônia (UNIR) para atender ao perfil proposto no Projeto Político Pedagógico (PPP) do curso em estudo.

O autor apresenta em sua pesquisa algumas inquietações sobre os professores que estão sendo formados na UNIR para o ensino de Química, ao destacar a ausência de um senso crítico quanto ao processo de ensino e aprendizagem dos profissionais formados. Poucos estão preocupados com a aprendizagem de seus alunos. O ensino está arraigado em uma abordagem conteudista que não permite aos docentes discernir sobre o que é relevante ou não para a aprendizagem dos educandos, sobre a relevância e a aplicabilidade dos conteúdos (Ramos, 2014).

Ao olhar e ler a pesquisa de Ramos (2014) notam-se convergências com a dissertação em andamento, sobretudo quando o autor descreve o cenário investigativo e apresenta a seguinte questão: "quais disciplinas contribuíram para a minha formação" (p.16). Essa pergunta se relaciona com o problema da dissertação da qual esse artigo faz parte: quais as contribuições do estágio supervisionado na formação de professores. Porém, Ramos (2014) fez uma investigação mais generalista, sua pesquisa estava centrada no curso como um todo, e não em uma disciplina específica. Enquanto, que a dissertação que este estudo faz parte focaliza em uma disciplina fundamental, por unir teoria e prática.

A questão central da dissertação em andamento, não gira em torno de como ocorre o processo, mas de como uma disciplina pode contribuir, modificar e formar professores, em especial, reflexivos. Profissionais que vão além dos conteúdos que não deve ser priorizado, mas construído. A reflexão como uma construção contínua do processo de ensino-aprendizagem. 
Seguindo na direção da formação de professores de Química, a dissertação de Corrêa (2013) traz para esfera educacional a discussão sobre os problemas encontrados por professores iniciantes em sua prática escolar. $\mathrm{O}$ autor apresenta o distanciamento entre o que foi aprendido durante a graduação e as situações que são encontradas no ambiente escolar, como resultado de uma formação precária.

Corrêa (2013, p.10) argumenta que o ambiente escolar constrói o professor, pois é um local de "interações humanas", repleto de "falas explícitas e implícitas - proferidas e/ou interiorizadas - tecem um diálogo constante". São esses diálogos e vivências do ser e fazer que corroboram para o desenvolvimento da práxis docente.

Alves dos Santos (2017) investiga em sua tese a relação dialética entre formação de professores de Química e trabalho docente na Universidade Federal de Goiás (UFG). Dentro dessa busca, a autora busca responder algumas perguntas: quem são os docentes e discentes da UFG; como está sendo construída a identidade profissional dos futuros professores; qual a relação entre formação e trabalho na perspectiva dos professores e alunos do curso de Química; qual a função social do professor para os licenciandos.

Ao observar esses questionamentos e realizar a leitura, observaram-se poucas intersecções do trabalho da autora com a dissertação em andamento. A autora segue um caminho investigativo direcionado para a formação e o trabalho docente em sentido político, participativo dos movimentos sociais. É perceptível na escrita de Alves dos Santos (2017) o destaque do professor como agente de transformação social. Baseada nesse princípio, a autora investiga a relação da formação e do trabalho docente como instrumentos de transformação política e pedagógica da práxis.

Já Castro (2014) alinha seu pensamento em torno das concepções de licenciandos e professores da educação básica sobre o estágio supervisionado do curso de Química da Universidade Federal de Juiz de Fora (UFJF). Na realização dessa tarefa, o autor apresenta as diferenças entre o modelo de racionalidade técnica e racionalidade prática. $\mathrm{O}$ mesmo buscou evidenciar essas diferenças pela investigação dos professores supervisores do estágio (formados no modelo de racionalidade técnica) e de licenciandos (formados no novo modelo de racionalidade prática) para entender as mudanças ocorridas e seus impactos na formação dos professores.

Além disso, Castro (2014) buscou identificar com seus resultados se essa mudança de modelo trouxe modificações ao Estágio Supervisionado (ES). Após a realização da pesquisa, o autor concluiu que houve modificações no modelo de estágio e que esse colaborou na formação dos professores. Porém, os dados não foram satisfatórios quanto ao desenvolvimento da disciplina de ES, pois se esperava que a disciplina oportunizasse uma parceria maior entre universidade e escola para que tanto os estagiários, quanto os professores formadores tivessem a oportunidade de desenvolver sua prática e colaborassem para a valorização do estágio supervisionado.

A pesquisa de Castro (2014) está alinhada com a pesquisa em curso, pois à medida que o autor investiga as concepções dos estagiários e dos professores formadores ele identifica as contribuições do estágio na formação docente. No entanto, a dissertação 
do PGECM vai além, ao investigar as contribuições do estágio para a formação de professores reflexivos, ou seja, ela busca saber se no desenvolvimento da práxis docente são feitos direcionamentos sobre o papel que o professor tem no processo educativo; se o ES possibilita o desenvolvimento da relação teoria e prática como momento de integração entre o saber e o fazer; se lhes fornece bases teórico-metodológicas para exercer e modificar a ação pedagógica.

Corrêa (2015) segue por um caminho semelhante ao de Castro (2014), mas ele direciona a sua pesquisa para questões como identidade e saberes docentes, prática pedagógica, autonomia e dentre outros temas. A autora, como tantos outros já citados, aborda a questão da formação do professor baseado no modelo de racionalidade técnica, destacando a necessidade de repensá-lo para que se possa formar "um profissional que seja autor de sua prática e que domine competências e habilidades especializadas" (p.9).

São destaques no processo formativo, as vivências e concepções construídas ao longo da vida, juntamente com os saberes e práticas que vão fundamentando a identidade docente. Essa não pode ser considerada acabada, pois representa um processo contínuo aliado dos conhecimentos adquiridos antes, durante e pós-universidade.

Segundo a autora, é necessário investigar e analisar os cursos de licenciatura em Química para compreender qual o perfil de professor que se quer formar e qual o perfil que está sendo formado, por isso a relação direta entre saberes e identidade docente. Ao fim dessa busca, Corrêa (2015) mostra que o profissional formado apresenta capacidades direcionadas a um "mercado diversificado, com pouco destaque para a docência".

Agora, Arrigo (2015) direciona sua pesquisa para uma questão mais profunda, a formação inicial reflexiva de professores em Química, baseada na técnica de microensino. Essa é comumente usada nos estágios supervisionados. A autora fundamenta seu trabalho no pensamento reflexivo de Schön $(1995 ; 2000)$ para identificar momentos de questionamento, estruturação e reestruturação da prática docente.

A dissertação da autora converge com a pesquisa ora em curso, desenvolvida dentro do IFCE, contudo Arrigo (2015) trabalho a formação do professor reflexivo direcionado a prática de microensino. Já a dissertação do PGECM, quer compreender a relação teóricoprática dentro dos estágios supervisionados para a formação do professor artista-reflexivo no ensino de Química.

Suart (2016), em sua tese, traz o Processo de Reflexão Orientada como uma proposta metodológica que possibilite ao futuro professor elaborar e avaliar sua prática docente direcionada para o processo de ensino-aprendizagem. A proposta da autora era o desenvolvimento de uma sequência de propostas de aulas que seriam pensadas, aplicadas e repensadas. Todo esse processo seria orientado e repensando em conjunto, baseado na alfabetização científica.

Ao fim do trabalho, a autora inferiu que os licenciandos apresentaram evoluções quanto ao processo metodológico de construção das aulas. Ademais, os alunos puderam expor suas dificuldades e superá-las através do desenvolvimento de uma postura crítica sobre a sua prática docente no processo de ensino e aprendizagem em Química. 
Logo, as pesquisas analisadas apresentam pensamentos diversos a respeito dos descritores investigados e trouxeram contribuições e perspectivas para a dissertação em curso, além de mostrar a importância da realização da mesma.

\section{CONSIDERAÇÕES FINAIS}

Após o mapeamento, análise e leitura dos textos, constatou-se que existe um número expressivo de pesquisas relacionadas à formação de professores, estágio supervisionado e relação teoria e prática, mas são poucas as pesquisas com essa tríade que se relacionam com o ensino de Química. Porém, esse número obteve um crescimento em 2016. Observouse, que a maioria das pesquisas analisadas vem da Região Sul e Sudeste do país, sendo poucos trabalhos realizados com esse viés na região Norte e Nordeste, em especial, no Estado do Ceará.

Na realização da presente pesquisa, nota-se o encontro de saberes no que concerne ao amplo interesse em compreender os processos envolvidos na formação docente, em especial o papel que a relação teoria e prática pode desempenhar. Além disso, constata-se a preocupação pelas atividades desenvolvidas no espaço do estágio supervisionado como um momento de concepção da práxis. Contudo, poucas foram as pesquisas realizadas com esse interesse voltado ao ensino de Química.

Constatou-se que algumas dissertações e teses apresentam objetivos semelhantes aos da dissertação em andamento, contribuindo para direcionamentos sobre a formação de professores; legislações relacionadas à formação de professores e ao estágio supervisionado; prática de ensino e discussões sobre o docente como um profissional reflexivo.

Ademais, observou-se que existem poucas pesquisas em nível de Pós-Graduação relacionadas à tríade formação de professores, estágio supervisionado e relação teoria e prática no ensino de Química, precisando de mais produções nesse sentido, o que embasa a relevância desse Estado da Questão e da pesquisa dissertativa que está sendo escrita para que se possa aprofundar a discussão dessas questões no âmbito acadêmico.

\section{AGRADECIMENTOS}

Agradecemos à Coordenação de Aperfeiçoamento de Pessoal de Nível Superior (CAPES) e ao Programa de Pós-Graduação em Ensino de Ciências e Matemática (PGCEM) do Instituto Federal de Educação, Ciência e Tecnologia do Ceará (IFCE) pelo financiamento para realização da pesquisa. 


\section{REFERÊNCIAS}

Alves dos Santos, J. D. (2017). A formação no curso de licenciatura em química UFG/ Goiânia: a relação entre a formação e o trabalho docente $(254$ f). Tese de Doutorado - Instituto de Química, UFG, Goiânia. Recuperado em 10 de agosto, 2017, de https:// repositorio.bc.ufg.br/tede/handle/tede/6920.

Arrigo, V. (2015). Estudo sobre as reflexões dos licenciandos em química nas atividades de microensino: implicações para a formação inicial docente. (124 f). Dissertação de Mestrado - Centro de Ciências Exatas, UEL, Londrina. Recuperado em 27 de outubro, 2017, de http://www.bibliotecadigital.uel.br/document/?code=vtls000202038.

Bardin, L. (2016). Análise de conteúdo. $1^{\mathrm{a}}$ ed. São Paulo: Edições 70.

Brasil, MEC/CNE/CP, Resolução $n^{o}$ 2, de $1^{\circ}$ de julho de 2015. Define as Diretrizes Curriculares Nacionais para a formação inicial em nível superior (cursos de licenciatura, cursos de formação pedagógica para graduados e cursos de segunda licenciatura) e para a formação continuada.

Brasil, Parecer CNE/CES n.1.303, 06 de novembro de 2001 (2001). Diretrizes Curriculares Nacionais para os Cursos de Química. Recuperado em 10 de novembro, 2017, de http:// portal.mec.gov.br/cne/arquivos/pdf/CES1303.pdf.

Carvalho, A. M. P. de, \& Gil-Pérez, D. (1995). Formação de professores de Ciências: tendências e inovações. Tradução de Sandra Venezuela. $2^{a}$ ed. São Paulo: Cortez.

Castro, S. I. (2014). Concepções de licenciandos do curso de química da Universidade Federal de Juiz de Fora e professores de química da educação básica sobre o estágio supervisionado (153 f). Dissertação de Mestrado - Instituto de Ciências Exatas, UFJF, Juiz de Fora. Recuperado em 04 de agosto, 2017, de https://repositorio.ufjf.br/jspui/ handle/ufjf/864.

Corrêa, R. G. (2015). Formação inicial de professores de química: discursos, saberes e práticas. (167 f). Tese de Doutorado - Centro de Ciências Exatas e Tecnologias, UFSCar, São Carlos. Recuperado em 05 de outubro, 2017, de https://repositorio.ufscar.br/handle/ ufscar/6346.

Corrêa, T. H. B. (2013). Os anos iniciais da docência em química: da universidade ao chão da escola (98 f). Dissertação de Mestrado - Faculdade de Ciências Humana, UNIMEP, Piracicaba, 2013. Recuperado em 05 de junho, 2017, de https://www.unimep.br/phpg/ bibdig/aluno/visualiza.php?cod=1075.

Fonseca, C. V. (2014). A formação de professores de química em instituições de ensino superior do Rio Grande do Sul: saberes, práticas e currículos (325 f). Tese de Doutorado - Faculdade de Educação, UFRGS, Porto Alegre. Recuperado em 14 de outubro, 2017, de http://www.lume.ufrgs.br/handle/10183/104466.

Franco, M. L. P. B. (2005). Análise de conteúdo. $2^{\mathrm{a}}$ ed. Brasília: Liber Livro Editora. Gil, A. C. (2017). Como elaborar projetos de pesquisa. $6^{\text {a }}$ ed. São Paulo: Atlas.

Maldaner, O. A. (2006). A formação inicial e continuada de professores de Química: professores/pesquisadores. 2. ed., Ijuí: Unijuí. (Coleção Educação em Química).

Nóbrega-Therrien, S.M. \& Therrien, J. (2004). Trabalhos científicos e o estado da questão: reflexões teóricos-metodológicas. Revista Estudos em avaliação educacional. São Paulo, 
5(30), jul-dez. Recuperado em 23 de junho, 2017, de http://publicacoes.fcc.org.br/ojs/ index.php/eae/article/view/2148/2105.

Nóbrega-Therrien, S.M. \& Therrien, J. (2010). O estado da questão: aportes teóricosmetodológicos e relatos de sua produção em trabalhos científicos. In: Farias, Isabel Sabino de; NUNES, João Batista de Carvalho; Nóbrega-Therrien, Silvia Maria. Pesquisa científica para iniciantes: caminhando no labirinto. Fortaleza, EdUECE.

Ramos, D. V. B. (2014). Formação de professores de química na Amazônia: um estudo na Universidade Federal de Rondônia (105f). Dissertação de Mestrado - Departamento de Ciências da Educação, UNIR, Porto Velho. Recuperado em 12 de outubro, 2017, de http://www.mestradoeducacao.unir.br/downloads/4064_denny_dissertacao.pdf.

Santos, D. M. (2016). Discutindo a formação dos professores de química da região noroeste do Paraná e suas práticas pedagógicas. (189f). Dissertação de Mestrado - Universidade Estadual do Paraná, UNESPAR, Paranavaí. Recuperado em 24 de setembro, 2017, de https://sucupira.capes.gov.br/sucupira/public/consultas/coleta/ trabalhoConclusao/viewTrabalhoConclusao.jsf?popup=true\&id_trabalho=4303668.

Schön, D. (1995). Formar professores como Profissionais Reflexivos. p.77-92. In: Nóvoa, A. (ed.). Os professores e a sua formação. $2^{\mathrm{a}} \mathrm{ed}$. Lisboa: Nova Enciclopédia.

Schön, D. (2000). Educando o profissional reflexivo: um novo design para o ensino e a aprendizagem. Porto Alegre: Artes Médicas Sul.

Silva, D. (2016). Análise da prática docente na formação de professores de química. (125 f). Tese de Doutorado - Instituto de Ciências Básicas da Saúde, UFRGS, Porto Alegre. Recuperado em 12 de setembro, 2017, de http://www.lume.ufrgs.br/ handle/10183/148956.

Suart, R. C. (2016). Formação inicial de professores de química: o processo de reflexão orientada visando o desenvolvimento de práticas educativas no ensino médio. (398 f). Tese de Doutorado - Faculdade de Educação, USP, São Paulo. Recuperado em 17 de agosto, 2017, de http://www.teses.usp.br/teses/disponiveis/81/81132/tde-28062016100904/pt-br.php.

Vacheski, G. M. O. (2016). Atividades sobre a perspectiva CTS na formação inicial de professores de química: implicações para o desenvolvimento profissional docente (2003 f). Dissertação de Mestrado - Centro de Ciências Exatas, UEL, Londrina. Recuperado em 20 de junho, 2017, de http://www.bibliotecadigital.uel.br/document/?code=vtls000207245. 